\title{
Hydrocele Following Laparoscopic Cholecystectomy
}

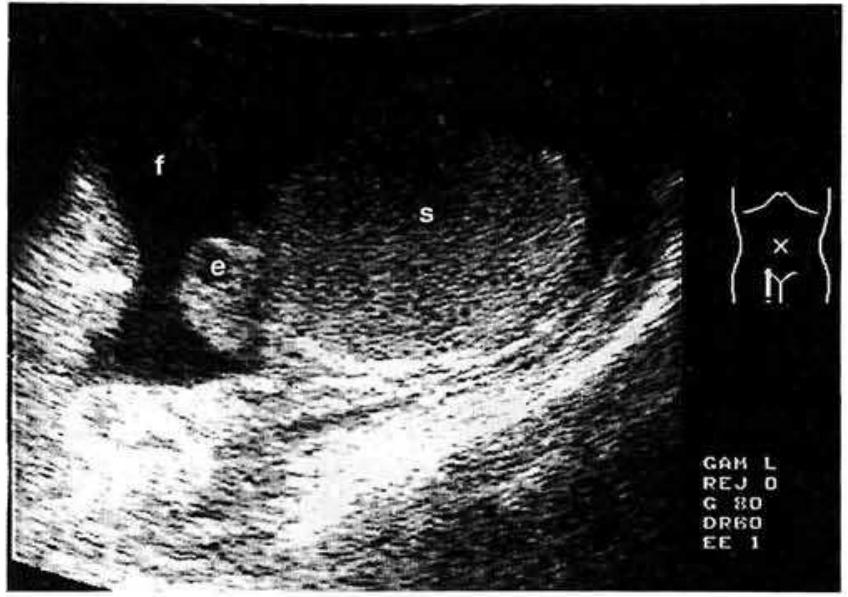

Figure 1: Postoperative ultrasonography of the right scrotum showing a hydrocele; $s=$ scrotum, $e=$ epididymis, $f=$ hydrocele fluid.

In the literature, specific complications following laparoscopic cholecystectomy are bile duct injury, bile leak, hemorrhage, retained stones, wound infection, ileus and pulmonary problems ( 1 $5)$. We report about the occurrence of a hydrocele after laparoscopic cholecystectomy in a 54-year-old male patient with cholocystolithiasis and cholecystitis, a complication which has, according to our knowledge, not yet been described. During laparoscopic cholecystectomy a hydropic gallbladder with an inflamed and thickened wall and severe adhesions between the gallbladder and the colon were found rendering surgical preparation around the Calot triangle difficult. Maintaining the pneumoperitoneum over a longer period of time and frequent irrigation became necessary but the operation could be finished without major difficulties or complications. On the first post-operative day the patient suffered from a slight swelling of the right scrotum, had a temperature of 38 degrees Celsius and a WBC of 15000 . Ultrasonography of the testes showed various cystic formations with air and fluid in the right scrotum. The epididymis was enlarged with central hypodense cystic arestet (Figure 1). The parenchyma of the right testicle was homogenous and without pathological findings. Apart from an enlargement of the epididymis the findings in the left scrotum were normal. Under local therapy, administration of antibiotics and antiphlogistics, the swelling, temperature and leucocytosis decreased rapidly and the patient was discharged free of symptoms on the seventh post-operative day. Ultrasonographic control after three weeks showed completely normal findings.

Since there was no evidence of hernia in the patient's history or on physical examination we assume that the obliterated vaginal process may have been reopened by the high intraabdominal pressure due to the pneumoperitoneum maintained for a longer period of time. After evacuation of the pneumoperitoneum at the end of the procedure the vaginal process reclosed and fluid and gas were retained in the scrotum, the latter being quickly reabsorbed. To avoid this potentially dangerous complication (inflammation of the hydrocele) we recommend keeping the intraabdominal pressure as low as possible and removing any intra-abdominal fluid collections at the end of the procedure.

W. Kauer*, I. Brune, H. Feussner, R. Hartung, J. R. Siewert Department of Surgery* and Urology

Technical University of Munich

Ismaninger Straße 22

81675 München, Germany 


\section{References}

1. Meyers WC: A prospective analysis of 1518 laparoscopic cholecystectomies. New Engl. J. Med. 1991; 324: 1073-1078.

2. Wolfe BM, Gardiner BN, Leary BF et al.: Endoscopic cholecystectomy: an analysis of complications. Arch. Surg. 1991; 126: 1192 $-1196$.

3. Bailey RW, Zucker KA, Flower JL et al.: Laparoscopic cholecys- tectomy: experience with 375 consecutive patients. Ann. Surg. 1991; 214: $531-540$.

4. Cuschieri A, DuBois F, Moniel $J$ et al.: The European experience with laparoscopic cholecystectomy. Am. J. Surg. 1991; 161: 385387.

5. Larson GM, Vitale GC, Casey $J$ et al:: Multipractice analysis of laparoscopic cholecystectomy in 1983 patients. Am. J. Surg. 1992; 163: $221-226$ 